\title{
Do pediatric healthcare providers know how to use metered dose inhaler plus spacer devices?
}

\author{
Kelechi Iheagwara ${ }^{a}$, Iman Sharif ${ }^{\mathrm{b}, *}$, Philip 0. Ozuah ${ }^{\mathrm{a}}$ \\ ${ }^{a}$ Albert Einstein College of Medicine/Children's Hospital at Montefiore, Bronx, NY, USA \\ ${ }^{b}$ Albert Einstein College of Medicine/Children's Hospital at Montefiore, Residency Program in Social \\ Pediatrics, 3544 Jerome Avenue, Bronx, NY 10467, USA
}

Received 2 January 2005; accepted 18 January 2005

Summary We tested whether health practitioners correctly Ised NiD-spacer devices. Of 122 subjects, $89 \%$ had instructed a patisnt on insing a spacer. Whils. performance with the Aerochamben vas e e bes:, only $3 \%$ correctly viernonstrated all the steps for that devire.

(c) 2005 Gelerail Practice Airwavs Grour. PAblished by Elsevier Ltd. All rights reserved.

\section{Introduction}

Over the past several years, there has been a surge in the manufacture of different types of spacer devices for use with metered dose inhalers (MDIs). The mode of use for these devices differs, depending particularly upon the presence or absence of a valved chamber. Pediatric healthcare providers frequently instruct patients on the use of MDI and spacer devices. However, no studies have tested whether or not providers are themselves able to use different spacer devices correctly.

\footnotetext{
Presented in part at the annual meetings of the Eastern Society for Pediatric Research in Connecticut, March 2003 and the Pediatric Academic Societies in Seattle, WA, May 2003.

* Corresponding author. Tel.: +1 718920 2822; fax: +1 7185155416 .

E-mail address: isharif@montefiore.org (I. Sharif).
}

We report on a pilot study to determine whether pediatric health practitioners correctly used the MDI-spacer devices that they prescribe and demonstrate to patients.

\section{Method}

We surveyed pediatric attendings, residents and nurses at an inner-city academic medical center in the Bronx. The study was approved by the Institutional Review Board of Montefiore Medical Center. First, subjects were asked whether they had ever prescribed spacer devices, and whether they had ever instructed patients in their use. Then, they were shown a series of commonly used spacer devices: (1) the two-way valve AeroChamber Plus with mask (Monaghan Medical, Plattsburgh, NY); (2) the one-way valve OptiChamber with mouth-piece (HealthScan Products Inc., Cedar 
Table 1 Proportion of pediatric healthcare providers who correctly demonstrated the steps of MDI-spacer use for three spacer devices $(N=122)$.

\begin{tabular}{llcc}
\hline & Aerochamber Plus $^{\mathrm{a}}$ & Optihaler $^{\mathrm{b}}$ & Optichamber $^{\mathrm{c}}$ \\
\hline Shakes MDI & $67 \%$ & $3 \%$ & $33 \%$ \\
Assembles MDI-S correctly & $89 \%$ & $2 \%$ & $41 \%$ \\
Forms tight seal (for mask) & $61 \%$ & $\mathrm{~N} / \mathrm{A}$ & $\mathrm{N} / \mathrm{A}$ \\
Instructs patient to breathe in & $11 \%$ & $1 \%$ & $7 \%$ \\
Correct no. breaths/length to hold breath & $31 \%$ & $0 \%$ & $7 \%$ \\
Waits correct interval/resets for next puff & $23 \%$ & $2 \%$ & $12 \%$ \\
NO steps correct & $7 \%$ & $97 \%$ & $59 \%$ \\
ALL steps correct & $3 \%$ & $0 \%$ & $3 \%$ \\
\hline
\end{tabular}

The criterion standard for correct demonstration was the manufacturers' instructions.

a two-way valve AeroChamber Plus with mask (Monaghan Medical, Plattsburgh, NY).

b one way valve OptiChamber with mouth-piece (HealthScan Products Inc., Cedar Grove, NJ).

c no-valve OptiHaler (HealthScan Products Inc., Cedar Grove, NJ).

Grove, NJ); and (3) the no-valve OptiHaler (HealthScan Products Inc., Cedar Grove, NJ). Subjects were asked to demonstrate how they would instruct a patient to use each device to administer two puffs of albuterol. Using the manufacturers' instructions as the criterion standard, the investigator coded the subject's performance as correct or incorrect. correctly demonstrated all the steps for that device (Table 1).

\section{Conclusion}

The National Asthma Education ard Prevention Program recommends that Fieatn care providers routinely clieck Dater ts use of MDI-spacers and cor tet their technique [1]. In this study, we found that while ifinact: spacers and instructed patients on their use, the majority did not know how to use a spacer device themselves. Asthma quality improvement efforts should include formal assessment of practitioner ability to use MDI-spacer devices, and formal instruction to ensure proper technique.

\section{Reference}

[1] National Institutes of Health. Expert Panel Report 2: Guidelines for the Diagnosis and Management of Asthma. National Institutes of Health, National Heart, Lung, and Blood Institute. Bethesda MD, July 1997; NIH Publication no. 97-4051. to use a spacer device. Whilst performance with the Aerochamber was the best, only $3 \%$ of subjects

Available online at www.sciencedirect.com<smiles>[Te]=Nc1ccc([Te]=[Te])cc1</smiles> 